\title{
Overlapping infection of Nocardia farcinica and Aspergillus fumigatus in a child with X-linked chronic granulomatous disease: a case report
}

\author{
Xiyan Tian ${ }^{1 \dagger}$, Qingmiao Shi ${ }^{2,3 \dagger}$, Peng Liu ${ }^{1 \dagger}$, Lulu Pang ${ }^{1}$, Peisheng Jia ${ }^{1}$, Lei Xie ${ }^{1}$, Xiaoxu Ma ${ }^{4}$, Ang Li ${ }^{2,33^{*}}$, \\ Zujiang $\mathrm{Yu}^{2,3^{*}}$ and Huaili Wang ${ }^{1 *}$
}

\begin{abstract}
Background: Chronic granulomatous disease (CGD) is a rare inherited primary immunodeficiency syndrome, manifested as recurrent infections and inflammatory complications. Although prophylactic treatment with antibiotics and antifungals improved the outcome of CGD patients, infections remain the major cause of mortality.

Case presentation: A boy aged 3 years and 8 months was admitted to hospital complaining of lip swelling with fever for half a month and neck abscess for 11 days. After a thorough examination, severe pneumonia, respiratory failure, oral and maxillofacial space infection, and perianal abscess were confirmed. However, his condition didn't improve after initial comprehensive therapy. Subsequently, overlapping infections of Nocardia farcinica and Aspergillus fumigatus were identified by metagenomic next-generation sequencing. He was treated with imipenem, linezolid, and voriconazole intravenously, plus taking oral compound sulfamethoxazole. Later, his condition improved. Through whole-exome sequencing, the child was ultimately diagnosed as $X$-linked chronic granulomatous disease (X-CGD) caused by CYBB gene mutation. Allogeneic hematopoietic stem cell transplantation was the potential sanative approach but there were no available human leukocyte antigen compatible donors for the child. The family requested to transfer to a superior hospital for further treatment. Two months later, we followed up the child's family. Unfortunately, the child had expired due to severe infection.
\end{abstract}

Conclusion: To our knowledge, this is the first case of overlapping infection of Nocardia farcinica and Aspergillus fumigatus identified by metagenomic next-generation sequencing in a child with X-CGD from China. For infectious pathogens that are hard to diagnosis by traditional detection methods, metagenomic next-generation sequencing is recommended as an adminicle or indispensable approach for microbial identification. Patients with X-CGD have poor prognosis, early diagnosis and intervention of X-CGD may reduce the mortality.

Keywords: Nocardia farcinica, X-linked chronic granulomatous disease, Metagenomic next-generation sequencing, Whole-exome sequencing, Early diagnosis, Case report

*Correspondence: lia@zju.edu.cn; johnyuem@zzu.edu.cn; whlek6527@126. com

${ }^{\dagger}$ Xiyan Tian, Qingmiao Shi, Peng Liu have contributed equally to this work and share first authorship

${ }^{1}$ Department of Pediatric Intensive Care Unit, The First Affiliated Hospital of Zhengzhou University, Zhengzhou, China

${ }^{2}$ Gene Hospital of Henan Province, The First Affiliated Hospital

of Zhengzhou University, Zhengzhou, China

Full list of author information is available at the end of the article

\section{Background}

Chronic granulomatous disease (CGD) is a rare and fatal primary phagocyte dysfunction disease $[1,2]$. The incidence of CGD in the west is about 1 in 200,000 to 1 in 250,000. However, its morbidity in China has not yet been eliminated. Due to the deficiency of nicotinamide adenine dinucleotide phosphate oxidase activity, phagocytes cannot kill peroxidase-positive bacteria and 
fungi, leading to repeated severe infections. Up to now, the reported pathogenic genes include $\mathrm{X}$-linked recessive inherited gene CYBB, which account for about $60 \%$, as well as autosomal recessive inherited genes CYBA, NCF1, NCF2, and NCF4 [3].

CGD mostly manifests as recurrent infections and inflammatory complications [4-6]. In North America, Aspergillus is the most major pathogen, followed by Staphylococcus, Burkholderia, Serratia, and Nocardia [7]. However, the European research found Staphylococcus aureus, Aspergillus, and Salmonella were the most frequently cultured microorganisms of CGD [8]. Whereas different from that, Aspergillus and Mycobacterium tuberculosis are most common pathogens in China [9]. Here, we report a case of overlapping infection of Nocardia farcinica and Aspergillus fumigatus identified by metagenomic next-generation sequencing (mNGS) and ultimately diagnosed as X-linked chronic granulomatous disease (X-CGD) through whole-exome sequencing (WES).

\section{Case presentation}

On July 28, 2020, a boy aged 3 years and 8 months was admitted to pediatric intensive care unit with a complaint of lip swelling with fever for half a month and neck abscess for 11 days. Physical examination revealed hyperthermia $\left(38.7^{\circ} \mathrm{C}\right)$, tachycardia $(165 \mathrm{bpm})$, tachypnea (60 bpm) and normal blood pressure $(102 / 74 \mathrm{mmHg})$ on the day of admission. His jaw to right upper lip was swollen, with tenderness and elevated skin temperature. Palpation suggested hepatomegaly and splenomegaly. Five anal fistulas could be seen and there were ulceration and scabs of the perianal skin.

Laboratory findings revealed elevated white blood cell count of $39.79 \times 10^{9} / \mathrm{L}$, percentage of neutrophils $87 \%$, procalcitonin $3.48 \mathrm{ng} / \mathrm{mL}$, C-reactive protein $221.6 \mathrm{mg} / \mathrm{L}$, erythrocyte sedimentation rate $44.00 \mathrm{~mm} / \mathrm{h}, 1,3-\beta$-Dglucan118.40 pg/mL, and galactomannan $1.06 \mathrm{ug} / \mathrm{L}$. While the hemoglobin $95.8 \mathrm{~g} / \mathrm{L}$, percent of lymphocytes $7.7 \%$, serum potassium $2.88 \mathrm{mmol} / \mathrm{L}$, serum sodium $128.0 \mathrm{mmol} / \mathrm{L}$, and albumin $23.8 \mathrm{~g} / \mathrm{L}$ were reduced. Arterial blood gas analysis showed hypoxemia of $51 \mathrm{mmHg}$. Other indicators, including neutrophil oxidative burst test, T-SPOT, blood culture, bone marrow aspiration cytology, bone marrow culture, mycoplasma titer, human parvovirus, antistreptolysin "O", and anti-neutrophil cytoplasmic antibody were negative.

Computed tomography (CT) scan indicated multiple clusters and nodular high-density shadows in both lung fields (Fig. 1), which were considered as bilateral lung infection. Besides, cystic density shadows were seen in the right maxillofacial region and submaxillary. Ultrasound found multiple enlarged lymph nodes on the bilateral neck, the larger ones were $12 \mathrm{~mm} \times 6 \mathrm{~mm}$ on the right and $11 \mathrm{~mm} \times 7 \mathrm{~mm}$ on the left. The right submaxillary region detected a hypoechoic area of about $35 \mathrm{~mm} \times 22.5 \mathrm{~mm}$, and the submental continuation to the left submaxillary region probed a range of about $79 \mathrm{~mm} \times 15 \mathrm{~mm}$ hypoechoic.

Severe pneumonia, respiratory failure, oral and maxillofacial space infection, and perianal abscess were confirmed. The child received empirical anti-infective treatment with intravenous meropenem, vancomycin, and fluconazole. However, in the early morning of the second day of admission, the child developed breathlessness and decreased oxygen saturation. Continuous positive airway pressure (CPAP) noninvasive ventilator was applied with the informed consent of the family. The following day, he was administered nasotracheal intubation and ventilator support due to hypoxic saturation (93\%) and severe carbon dioxide retention $(98 \mathrm{mmHg})$.

The child's condition didn't improve after initial therapy and an infrequent pathogen was doubted. On day 3 post admission, submandibular pus puncture was performed and the pus was tested through metagenomic next-generation sequencing (mNGS). Within $24 \mathrm{~h}$, it revealed 87 sequence readings of Nocardia farcinica genome (Table 1). The child was given oral compound sulfamethoxazole tablets. Besides, vancomycin was switched to linezolid and meropenem was changed to imipenem. $48 \mathrm{~h}$ later, special bacterial smear of pus indicated that weak acid-fast staining was positive, which was suspected of Nocardia. Moreover, the pus was cultured and the $N$. farcinica was identified after 5 days, further proving the pathogen detected by mNGS.

On day 5 of admission, bronchoalveolar lavage fluid (BALF) was detected by mNGS and the results showed 64 sequence readings of $N$. farcinica genome and 5 sequence readings of Aspergillus fumigatus genome (Table 1). While the galactomannan value reported from BALF was $\leq 0.25$. The child was considered an overlapping infection of $N$. farcinica and A. fumigatus. Moreover, special bacterial smear of BALF found positive weak acid-fast staining, which was suspected Nocardia. The antibiotics were adjusted to imipenem, linezolid, and voriconazole intravenously, plus taking oral compound sulfamethoxazole. Later, the child's condition improved.

Pursuing his medical history uncovered that he developed a fever 21 days after birth and was diagnosed with pulmonary Aspergillus infection. Perianal abscess appeared when he was 8 months old. It's necessary to be alert to immunodeficiency diseases. Thus, on the 8th day of admission, peripheral blood of the children and his parents were collected for whole-exome sequencing (WES). Twelve days later, WES reported c.121 locus $\mathrm{T}$ deletion mutation in the CYBB gene of the child 

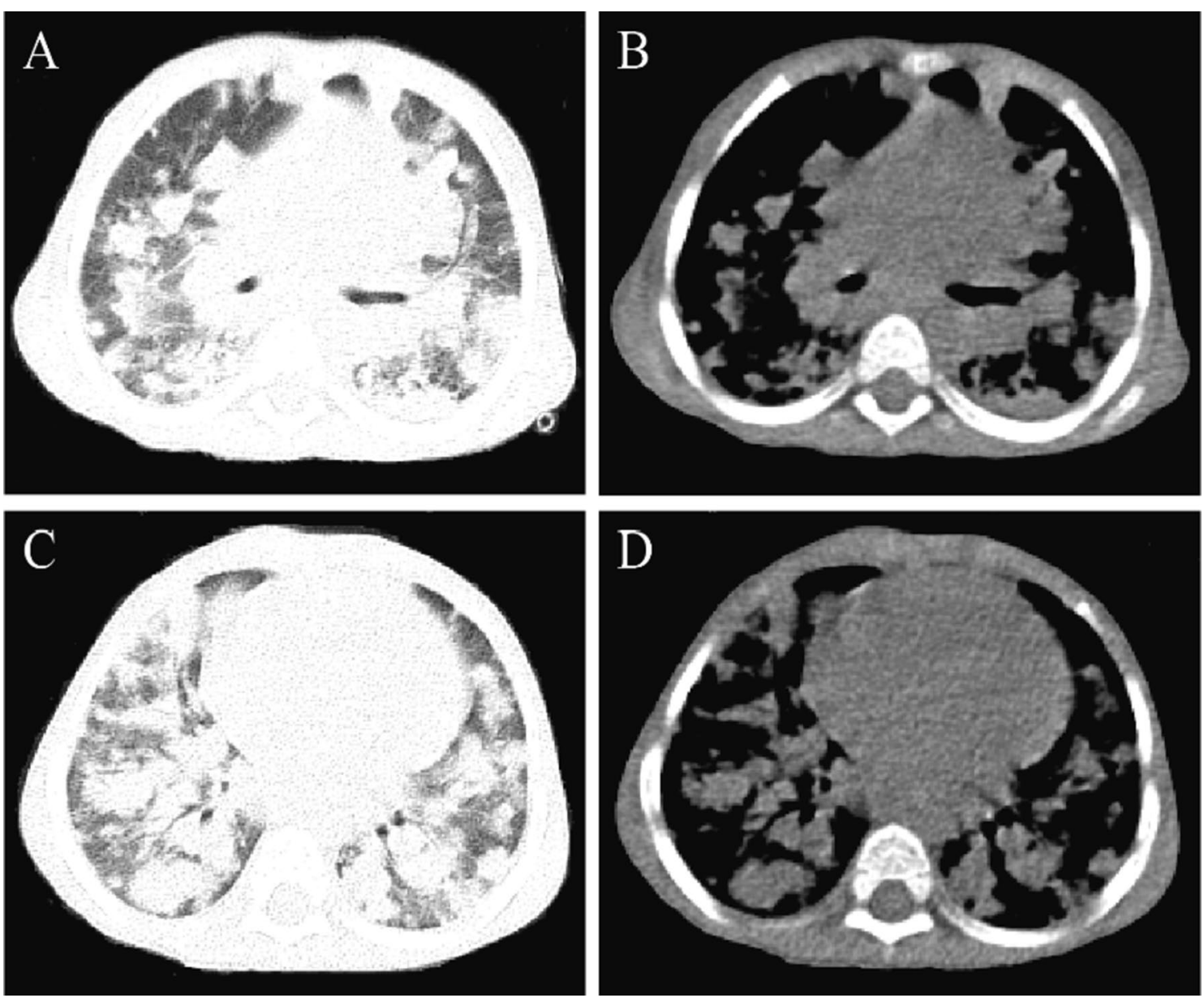

Fig. 1 Chest CT showed multiple clusters and nodular high-density shadows in both lung fields. $\mathbf{A}$ and $\mathbf{C}$ were lung window images; $\mathbf{B}$ and $\mathbf{D}$ were corresponding mediastinum window images

Table 1 The metagenomic next-generation sequencing results of the patient

\begin{tabular}{llll}
\hline Date & Specimen type & Pathogen & $\begin{array}{l}\text { Sequence } \\
\text { readings }\end{array}$ \\
\hline 2020.07 .31 & PUS & Nocardiafarcinica & 87 \\
2020.08 .03 & BALF & Nocardiafarcinica & 64 \\
& & Aspergillus fumigatus & 5 \\
\hline
\end{tabular}

(Fig. 2), which is related to X-linked chronic granulomatous disease (X-CGD). And his mother was found a carrier of X-CGD with the inherited c.121 locus $\mathrm{T}$ deletion mutation.

Combined with medical history, physical signs, auxiliary examinations, pathogen detection and genetic sequencing results, the child was diagnosed as X-CGD caused by CYBB gene mutation. Allogeneic hematopoietic stem cell transplantation (HSCT) was a potential sanative approach and his family expressed willingness to have a try. On September 19, the child's father and elder brother were administered human leukocyte antigen (HLA) typing test. On September 30, HLA typing results showed the child was 5/10 HLA-matched with his father or brother. There were no available HLA-compatible donors for the child. On October 1, the family requested to transfer to a superior hospital for further treatment. After informing them of the precautions in detail, the child was discharged. Two months later, we followed up with the child's family. Unfortunately, the child had expired due to severe infection. The detailed diagnosis and treatment process are shown in Fig. 3.

\section{Discussion and conclusions}

Nocardia species are gram-positive bacteria that grow aerobically and present various degrees of acid resistance [10]. Nocardia farcinica, a species of Nocardia, is a longneglected opportunistic bacterium of high mortality rate, 


\section{Reference $\quad A \quad T \quad T C C$ C A C C C}
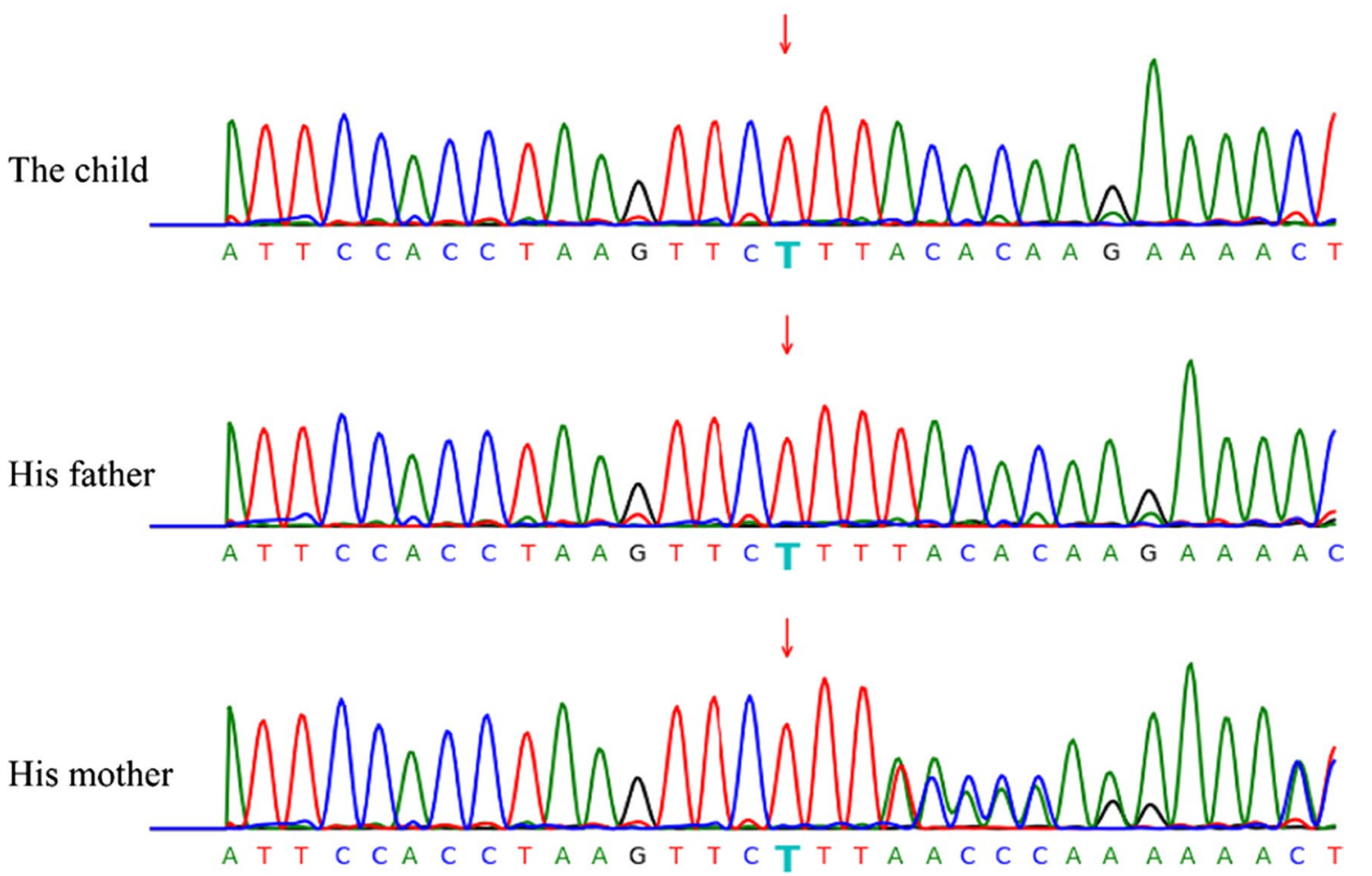

Fig. 2 WES revealed T deletion mutation in the CYBB gene of the child and his mother

which is prone to missed diagnosis owing to complexity of taxonomy and inexperience in traditional identification techniques $[11,12]$. In this case, mNGS was used to quickly and accurately detect that the child had both $N$. farcinica and A. fumigatus infection, thus providing effective assistance in diagnosis and treatment.

Accumulated evidence indicated that the mNGS has great advantages of wide coverage and higher sensitivity, which can identify multiple pathogens at one time, especially for pathogens with low positive rate of traditional testing methods [13-15]. According to a previous retrospective study, 14 samples from the patients diagnosed with nocardiosis were tested by both mNGS and culture. All 14 samples were positive for Nocardia by mNGS, but only 5 samples had positive culture results [16]. Another research reported a brain abscess caused by Nocardia diagnosed by Ziehl-Neelsen stain and mNGS, while the blood culture was negative [17]. However, the optimal timing for mNGS detection has not yet been determined, and the low specificity of mNGS also bring some challenges to clinical diagnosis [18].

In China, patients with CGD are predominantly male and generally have symptoms at an early age [9].
However, most cases were delayed diagnosed because of limited knowledge, leading to relative high mortality. The child in our case was infected with Aspergillus at 21 days of life and occurred perianal abscess at 8 months old, which were earliest clues of CGD. Whereas, this X-linked recessive hereditary disease was not identified until this admission, reminding us that our understanding of CGD needs to be improved. In this case, whole-exome sequencing acted an important function in the diagnosis of inherited diseases. Once CGD is suspected, wholeexome sequencing is a valid way to clarify the diagnosis.

Although prophylactic treatment with antibiotics and antifungals improved outcomes of CGD patients, infections remain a major cause of mortality. Particularly, previous study found that X-CGD patients generally had poorer survival than autosomal recessive CGD [8]. Prompt and effective therapy is of great importance. HSCT proved to be a practicable method to rescue CGD patients [19]. However, HSCT has its own limitations, such as limited donor availability, risks of pretreatment radiotherapy and chemotherapy, and graft-versus-host disease. Lentiviral gene therapy for X-CGD is in research but has not been widely implemented [20]. Our pediatric 


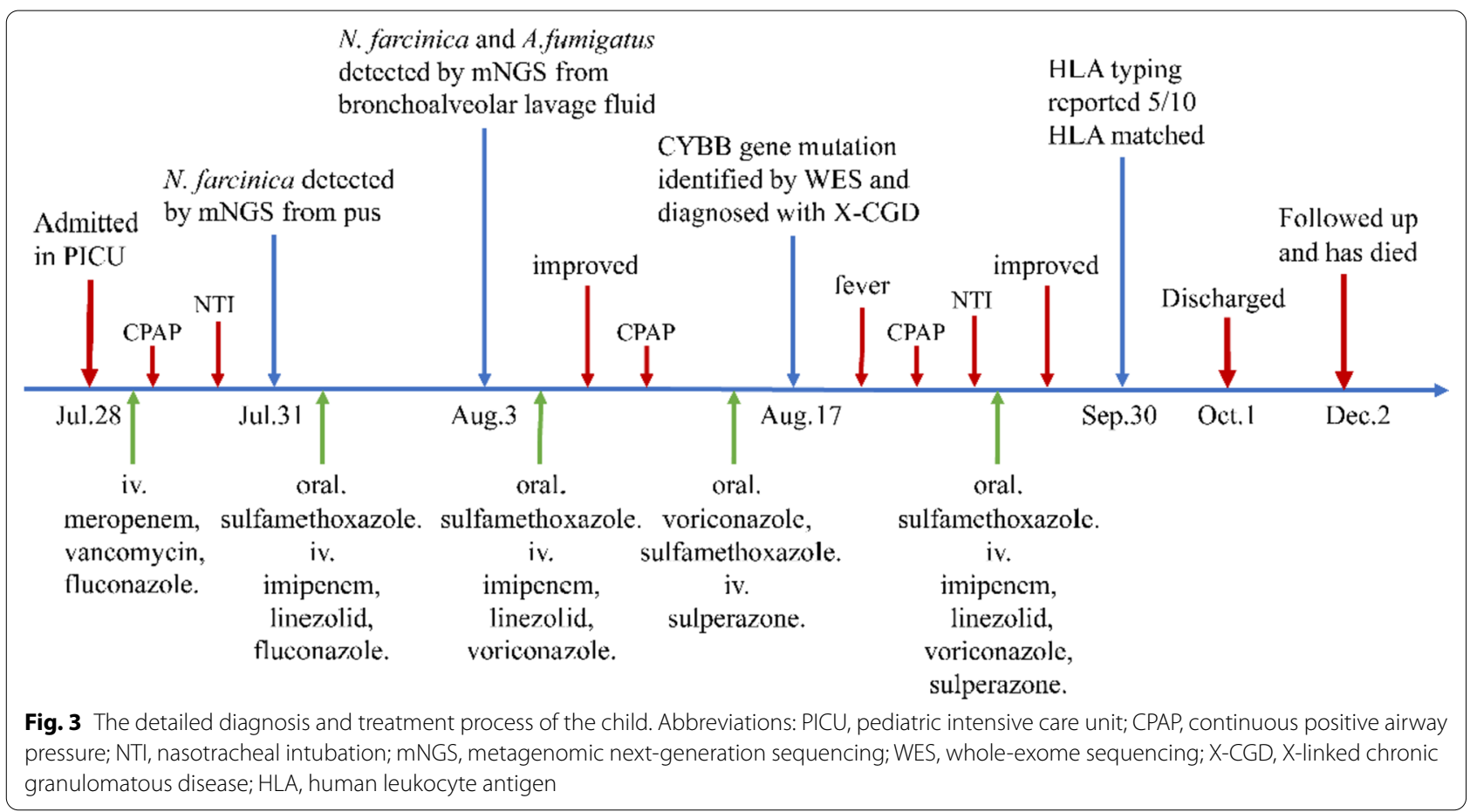

patient was haploidentical with his father or brother, especially because he had severe infections, causing high risks of conducting HSCT. Unfortunately, the child eventually died of multiple infectious complications and lost the opportunity for further treatment.

This case has some limitations. In the multidisciplinary diagnosis and treatment discussion, it was raised that the selection of empirical treatment was improper. The child was initially given antifungal treatment with fluconazole after admission. Fluconazole is a hydrophilic drug with small molecular size and low protein binding ratio, so it is the first choice for urinary tract and abdominal Candida infection. However, the child was presented with lung infection and he had a history of Aspergillus infection. Thus, Aspergillus should be considered in the initial antifungal therapy. After the mNGS indicated A. fumigatus infection, the fluconazole was changed to voriconazole. Voriconazole is a lipophilic drug with a wide distribution in lung tissue, alveoli, and epithelial lining fluid, making it the drug of choice for pulmonary Aspergillus.

To our knowledge, this is the first case of an overlapping infection of Nocardia farcinica and Aspergillus fumigatus identified by mNGS in an X-CGD child from China. For infectious pathogens hard to diagnosis by traditional detection methods, mNGS is recommended as an adminicle or indispensable approach for identifying microorganisms. The patient with X-CGD has a poor prognosis, early diagnosis and intervention of X-CGD may reduce mortality.

\section{Abbreviations}

CGD: Chronic granulomatous disease; X-CGD: X-linked chronic granulomatous disease; $m N G S$ : Metagenomic next-generation sequencing; WES: Wholeexome sequencing; HSCT: Hematopoietic stem cell transplantation; HLA: Human leukocyte antigen; CPAP: Continuous positive airway pressure.

\section{Acknowledgements}

We thank all the pediatric intensive care unit and the laboratory colleagues involved in the diagnosis and treatment of the child at the First Affiliated Hospital of Zhengzhou University.

\section{Authors' contributions}

XT, QS and PL designed the study. XT collected clinical data. QS and PL wrote the original manuscript. LP, PJ, LX, and XM involved in the clinical management and interpreted the data. AL guided mNGS and WES experiment and performed data analysis. ZY and HW conceptualized this work and revised the draft. $A L, Z Y$, and $H W$ revised and supervised the paper. $A L, Z Y$, and $H W$ are co-corresponding authors. XT, QS and PL are co-first authors. All authors read and approved the final manuscript.

\section{Funding}

This work was equally funded and supported by Chinese National Science and Technology Major Project 2018ZX10305410, Joint Construction Project of Henan Province Medical Science and Technology Program grant LHGJ20200340, Henan Province Science and Technology Research Project grant 212102310442. The funders had no role in study design, data collection and analysis, decision on publish, or preparation of the manuscript.

\section{Availability of data and materials}

All the data and materials in this report are from the authors on reasonable request. 


\section{Declarations}

Ethics approval and consent to participate

Not applicable.

\section{Consent for publication}

Written informed consent was obtained from the patient's legal guardian for publication of this Case Report and any accompanying images.

\section{Competing interests}

All the authors declare there are no conflicts.

\section{Author details}

${ }^{1}$ Department of Pediatric Intensive Care Unit, The First Affiliated Hospital of Zhengzhou University, Zhengzhou, China. ${ }^{2}$ Gene Hospital of Henan Province, The First Affiliated Hospital of Zhengzhou University, Zhengzhou, China. ${ }^{3}$ Department of Infectious Diseases, The First Affiliated Hospital of Zhengzhou University, Zhengzhou, China. ${ }^{4}$ Department of Respiration, The First Affiliated Hospital of Zhengzhou University, Zhengzhou, China.

Received: 29 July 2021 Accepted: 9 December 2021

Published online: 20 January 2022

\section{References}

1. Roos D, Kuhns D, Maddalena A, Roesler J, Lopez J, Ariga T, et al. Hematologically important mutations: X-linked chronic granulomatous disease (third update). Blood Cells Mol Dis. 2010;45(3):246-65. https://doi.org/10. 1016/j.bcmd.2010.07.012

2. Weisser M, Demel U, Stein S, Chen-Wichmann L, Touzot F, Santilli G, et al. Hyperinflammation in patients with chronic granulomatous disease leads to impairment of hematopoietic stem cell functions. J Allergy Clin Immunol. 2016;138(1):219-28.e9. https://doi.org/10.1016/j.jaci.2015.11.028.

3. Chiriaco M, Salfa I, Di Matteo G, Rossi P, Finocchi A. Chronic granulomatous disease: clinical, molecular, and therapeutic aspects. Pediatr Allergy Immunol. 2016;27(3):242-53. https://doi.org/10.1111/pai.12527.

4. Aygun D, Koker M, Nepesov S, Koker N, Van Leeuwen K, De Boer M, et al. Genetic characteristics, infectious, and noninfectious manifestations of 32 patients with chronic granulomatous disease. Int Arch Allergy Immunol. 2020;181(7):540-50. https://doi.org/10.1159/000507366.

5. Paccoud O, Guery R, Poirée S, Jouvion G, Bougnoux M, Catherinot E, et al. Aspergillus felis in patient with chronic granulomatous disease. Emerg Infect Dis. 2019;25(12):2319-21. https://doi.org/10.3201/eid2512.191020.

6. Haidar G, Zerbe C, Cheng M, Zelazny A, Holland S, Sheridan K. Phellinus species: an emerging cause of refractory fungal infections in patients with X-linked chronic granulomatous disease. Mycoses. 2017;60(3):15560. https://doi.org/10.1111/myc.12573.

7. Marciano B, Spalding C, Fitzgerald A, Mann D, Brown T, Osgood S, et al. Common severe infections in chronic granulomatous disease. Clin Infect Dis. 2015;60(8):1176-83. https://doi.org/10.1093/cid/ciu1154.

8. Van Den Berg J, Van Koppen E, Ahlin A, Belohradsky B, Bernatowska E, Corbeel L, et al. Chronic granulomatous disease: the European experience. PLoS ONE. 2009;4(4): e5234. https://doi.org/10.1371/journal.pone. 0005234.

9. Gao L, Yin Q, Tong Y, Gui J, Liu X, Feng X, et al. Clinical and genetic characteristics of Chinese pediatric patients with chronic granulomatous disease. Pediatr Allergy Immunol. 2019;30(3):378-86. https://doi.org/10. 1111/pai.13033.

10. Huang L, Chen X, Xu H, Sun L, Li C, Guo W, et al. Clinical features, identification, antimicrobial resistance patterns of Nocardia species in China: 2009-2017. Diagn Microbiol Infect Dis. 2019;94(2):165-72. https://doi. org/10.1016/j.diagmicrobio.2018.12.007.

11. Wilson J. Nocardiosis: updates and clinical overview. Mayo Clin Proc. 2012;87(4):403-7. https://doi.org/10.1016/j.mayocp.2011.11.016.

12. Budzik J, Hosseini M, Mackinnon A, Taxy J. Disseminated Nocardia farcinica: literature review and fatal outcome in an immunocompetent patient. Surg Infect. 2012;13(3):163-70. https://doi.org/10.1089/sur.2011. 012.
13. Wang C, Li A, Shi Q, Yu Z. Metagenomic next-generation sequencing clinches diagnosis of leishmaniasis. Lancet (London, England). 2021;397(10280):1213. https://doi.org/10.1016/s0140-6736(21)00352-4.

14. Zhang X, Guo L, Liu L, Shen A, Feng W, Huang W, et al. The diagnostic value of metagenomic next-generation sequencing for identifying Streptococcus pneumoniae in paediatric bacterial meningitis. BMC Infect Dis. 2019;19(1):495. https://doi.org/10.1186/s12879-019-4132-y.

15. Li N, Cai Q, Miao Q, Song Z, Fang Y, Hu B. High-throughput metagenomics for identification of pathogens in the clinical settings. Small methods. 2021;5(1):2000792. https://doi.org/10.1002/smtd.202000792.

16. Weng S, Zhang H, Ai J, Gao Y, Liu Y, Xu B, et al. Rapid detection of Nocardia by next-generation sequencing. Front Cell Infect Microbiol. 2020. https:// doi.org/10.3389/fcimb.2020.00013.

17. Huang T, Chen Y, Zhang J, He R, Qu D, Ye Q, et al. Rapid and accurate diagnosis of brain abscess caused by Nocardia asiatica with a combination of Ziehl-Neelsen staining and metagenomics next-generation sequencing. Eur J Neurol. 2021;28(1):355-7. https://doi.org/10.1111/ene.14533.

18. Rossoff J, Chaudhury S, Soneji M, Patel S, Kwon S, Armstrong A, et al. Noninvasive diagnosis of infection using plasma next-generation sequencing: a single-center experience. Open Forum Infect Dis. 2019. https://doi.org/ 10.1093/ofid/ofz327.

19. Güngör T, Teira P, Slatter M, Stussi G, Stepensky P, Moshous D, et al. Reduced-intensity conditioning and HLA-matched haemopoietic stem-cell transplantation in patients with chronic granulomatous disease: a prospective multicentre study. Lancet (London, England). 2014;383(9915):436-48. https://doi.org/10.1016/s0140-6736(13)62069-3.

20. Kohn D, Booth C, Kang E, Pai S, Shaw K, Santilli G, et al. Lentiviral gene therapy for $X$-linked chronic granulomatous disease. Nat Med. 2020;26(2):200-6. https://doi.org/10.1038/s41591-019-0735-5.

\section{Publisher's Note}

Springer Nature remains neutral with regard to jurisdictional claims in published maps and institutional affiliations.

Ready to submit your research? Choose BMC and benefit from:

- fast, convenient online submission

- thorough peer review by experienced researchers in your field

- rapid publication on acceptance

- support for research data, including large and complex data types

- gold Open Access which fosters wider collaboration and increased citations

- maximum visibility for your research: over $100 \mathrm{M}$ website views per year

At BMC, research is always in progress.

Learn more biomedcentral.com/submissions 